\title{
Antena Mikrostrip Linear Array dengan Slot $U$ untuk Internal Pesawat Televisi pada Band Frekuensi UHF
}

\author{
Aditya Wardhani dan Ikhwana Elfitri* \\ Jurusan Teknik Elektro, Fakultas Teknik, Universitas Andalas \\ *Corresponding author, e-mail: ikhwana@ft.unand.ac.id
}

\begin{abstract}
Abstrak - Televisi (TV) adalah salah satu media informasi yang sangat populer di masyarakat. Antena TV pada frekuensi UHF yang saat ini tersedia umumnya berukuran relatif besar dan dipasang di luar pesawat TV sehingga kurang cocok apabila diterapkan pada peralatan yang bersifat portable. Pada tulisan ini dirancang sebuah antenna mikrostrip dengan slot berbentuk $U$ dan disusun secara linear array empat elemen. Hasil simulasi menggunakan perangkat lunak Zeland IE3D menunjukkan bahwa antena yang dirancang mampu bekerja pada rentang frekuensi $486-734 \mathrm{MHz}$ (keseluruhan rentang frekuensi UHF) dan memiliki ukuran yang relatif kecil yakni 80 x $27 \mathrm{~cm}$, sehingga cocok dipasang pada TV dengan ukuran minimal 32 inchi. Hasil simulasi juga memperlihatkan bahwa antena yang dirancang memiliki Gain lebih besar dari $3.5 \mathrm{~dB}$.
\end{abstract}

Kata Kunci : Ultra High Frequency (UHF), Antena Mikrostrip,U-Slot.

\begin{abstract}
Television (TV) can be considered as the most popular information media. TV at Ultra High Frequency (UHF) normally has larger size of antenna than the TV terminal itself, and is usually connected as external equipment so that they are not suitable for portable TV terminal. In this paper, a 4-element linear array microstrip antenna with U-slot has been designed. Simulation with Zeland IE3D shows that the proposed antenna is capable of operating at frequency of $486-734 \mathrm{MHz}$ (within overall UHF band) and has a relatively smaller size with dimension of $80 \times 27 \mathrm{~cm}$, hence it is suitable for TV with screen size larger than 32 inch. The results of the experiment also show that the antenna can achieve Gain higher than $3.5 \mathrm{~dB}$.
\end{abstract}

Keywords : Ultra High Frequency (UHF), Microstrip Antenna, U-Slot

\section{Pendahuluan}

Antena adalah salah satu komponen penting dalam sistem komunikasi. Pada penerimaan siaran Televisi (TV) pada frekuensi UHF, antena yang digunakan pada umumnya berukuran besar dan mesti dipasang pada tempat yang lebih tinggi. Karena itu, sebuah antena yang lebih kecil dan dapat dipasang pada bagian dalam pesawat TV sangat diperlukan. Salah satu antena yang memenuhi kriteria tersebut adalah antena mikrostrip. Banyak penelitian yang telah dilakukan menggunakan antena mikrostrip sebagai antena penerima TV, diantaranya adalah penelitian yang merancang antena mikrostrip dengan bentuk patch seperti angka empat untuk penerimaan siaran TV pada band UHF [1]. Penelitian selanjutnya juga merancang antena mikrostrip sebagai antenanya untuk penerimaan siaran TV pada jalur UHF, dengan model patch berbentuk trisula [2] dan juga dengan model patch berbentuk lingkaran [3]. Penelitian selanjutnya juga menggunakan antena mikrostrip sebagai antena penerimaan siaran TV pada band frekuensi UHF, tetapi dengan menambah slot berbentuk huruf U. Penelitian telah membuktikan bahwa penambahan slot $\mathrm{U}$ dapat memperbesar bandwidth $[4,5]$.

Pada paper ini dirancang sebuah antena mikrostrip linear array 4 elemen dengan slot berbentuk $U$ untuk penerimaan siaran TV. Diharapkan antena ini dapat meningkatkan portabilitas pesawat TV sehingga lebih memudahkan penggunanya.

\section{Tinjauan Pustaka}

Antena adalah suatu alat yang mengubah gelombang terbimbing dari saluran transmisi menjadi gelombang bebas di udara, dan sebaliknya. Antena digunakan untuk mengirim dan menerima gelombang elektromagnetik. Antena memiliki sifat resonansi, sehingga kerja dari sebuah antena bergantung kepada pemakaian dan penggunaan frekuensinya. Antena merupakan 
struktur transisi antara ruang bebas dengan alat pembimbing. Alat pembimbing atau dikenal dengan saluran transmisi adalah alat yang berfungsi sebagai penghantar atau penyalur energi gelombang elektromagnetik. Saluran transmisi dapat berupa saluran koaxial ataupun pipa dan digunakan sebagai alat transportasi energi elektromagnetik dari sumber transmisi ke antena atau dari antena ke penerima [6].

\subsection{Antena Mikrostrip}

Secara fisik antena mikrostrip adalah suatu konduktor metal yang menempel di atas ground plane yang diantaranya terdapat bahan dielektrik, seperti terlihat pada Gambar.1. Antena mikrostrip terdiri atas 3 bagian, yaitu patch, substrat, dan ground plane [7].

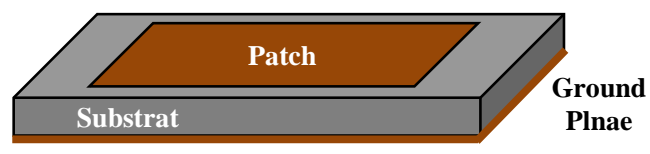

Gambar 1. Ilustrasi antena mikrostrip

Patch adalah bagian yang terletak paling atas dari antena. Patch terbuat dari bahan logam konduktor seperti tembaga atau emas. Patch adalah pemancar (radiator) yang berfungsi meradiasikan gelombang elektromagnetik ke udara.

Substrat berfungsi sebagai media penyalur gelombang elektromagnet dari sistem pencatuan. Karakteristik substrat sangat berpengaruh pada besar parameter parameter antena.

Ground plane yaitu lapisan paling bawah yang berfungsi sebagai reflektor yang memantulkan sinyal yang tidak diinginkan. Groundplane pada umumnya dirancang menggunakan bahan yang sama dengan patch.

\subsection{Parameter umum Antena Mikrostrip}

Parameter antena merupakan tolak ukur dari performa/kinerja suatu antena, oleh karena itu parameter antena adalah hal yang penting untuk diperhitungkan dalam merancang sebuah antena. Kinerja dari suatu antena dapat diukur dari beberapa parameter berikut ini [8].

\subsubsection{Frekuensi Resonansi}

Frekuensi resonansi sebuah antena dapat diartikan sebagai frekuensi kerja antena di mana pada frekuensi tersebut seluruh daya dipancarkan secara maksimal. Pada umumnya frekuensi resonansi menjadi acuan menjadi frekuensi kerja antena.

\subsubsection{VSWR (Voltage Standing Wave Ratio)}

Voltage Standing Wave Ratio (VSWR) adalah kemampuan suatu antena untuk bekerja pada frekuensi yang diinginkan. Pengukuran VSWR berhubungan dengan pengukuran koefisien refleksi dari antena tersebut. Perbandingan level tegangan yang kembali ke pemancar $\left(\mathrm{V}_{-}\right)$dan yang datang menuju beban $\left(\mathrm{V}_{+}\right)$ke sumbernya lazim disebut koefisien pantul atau koefisien refleksi yang dinyatakan dengan simbol $\Gamma$. Harga koefisien refleksi ini dapat bervariasi antara 0 (tanpa pantulan/match) sampai 1, yang berarti sinyal yang datang ke beban seluruhnya dipantulkan kembali ke sumbernya semula. Maka untuk pengukuran Voltage Standing Wave Ratio (VSWR), dinyatakan pada persamaan (1) :

$$
V S W R=\frac{1+|\Gamma|}{1-|\Gamma|}
$$

Besarnya VSWR yang ideal adalah 1, yang berarti semua daya yang diradiasikan antena pemancar diterima oleh antena penerima (match). Semakin besar nilai VSWR menunjukkan daya yang dipantulkan juga semakin besar dan semakin tidak match. Dalam prakteknya VSWR harus bernilai lebih kecil dari 2.

\subsubsection{Return Loss}

Return loss adalah perbandingan amplitudo dari gelombang yang direfleksikan terhadap amplitudo gelombang yang dikirimkan. Nilai return loss yang baik adalah di bawah $-9,54 \mathrm{~dB}$, nilai ini diperoleh untuk nilai VSWR $\leq 2$ sehingga dapat dikatakan nilai gelombang yang direfleksikan tidak terlalu besar dibandingkan dengan gelombang yang dikirimkan atau dengan kata lain, saluran transmisi sudah matching.

\subsubsection{Bandwidth}

Pemakaian suatu antena dalam sistem pemancar atau penerima selalu dibatasi oleh daerah frekuensi kerjanya. Pada range atau rentang frekuensi kerja tersebut antena dituntut harus dapat bekerja dengan efektif agar dapat menerima atau memancarkan gelombang pada band frekuensi tertentu. Daerah frekuensi kerja dimana antena masih dapat bekerja dengan baik itulah yang dinamakan dengan bandwidth. 


\subsubsection{Gain}

Gain adalah penguatan atau kemampuan pada antena yang berhubungan dengan directivity dan efisiensi antena. Ada dua jenis penguatan (gain) pada antena, yaitu penguatan absolut (absolute gain) dan penguatan relatif (relative gain). Penguatan absolut pada sebuah antena didefenisikan sebagai perbandingan antara intensitas pada arah tertentu dengan intensitas radiasi yang diperoleh jika daya yang diterima oleh antena teradiasi secara isotropic. Penguatan relatif didefenisikan sebagai perbandingan antara perolehan daya pada sebuah arah dengan perolehan daya pada antena referensi pada arah yang direferensikan juga. Daya masukan harus sama di antara kedua antena itu. Akan tetapi, antena referensi merupakan sumber isotropic yang lossless.

\subsubsection{Pola Radiasi}

Pola radiasi dapat disebut sebagai pola medan (field pattern) apabila yang digambarkan adalah kuat medan dan disebut pola daya (power pattern) apabila yang digambarkan pointing vektor. Seringkali pola medan dan daya disamakan ukurannya dengan mengacu pada nilai maksimum masing-masing. Pola daya biasanya diplot pada sebuah satuan logaritma atau lebih umum dalam desibel (dB). Pola radiasi dapat dibedakan beberapa macam yaitu [8]:

- Pola isotropik

Antena isotropik didefinisikan sebagai sebuah antena tanpa rugi-rugi secara hipopenelitian yang mempunyai radiasi sama besar ke setiap arah.

\section{- Pola directional}

Antena yang mempunyai pola radiasi atau pola menerima gelombang elektromagnetik yang lebih efektif pada arah-arah tertentu saja.

- Pola radiasi lobe (cuping)

Bagian-bagian dari pola radiasi ditunjukkan sebagai cuping-cuping yang bisa diklasifikasikan menjadi main (utama), side (samping), dan back (belakang). Main lobe ialah lobe/cuping radiasi yang memiliki arah radiasi maksimum. Side lobe adalah lobe/cuping selain main lobe sedangkan back lobe adalah lobe yang arahnya belawanan 180 derajat dengan main lobe. Side lobe dan back lobe merupakan minor lobe yang keberadaannya tidak diharapkan.

\subsection{Antena Mikrostrip Rectangular Slot $\boldsymbol{U}$}

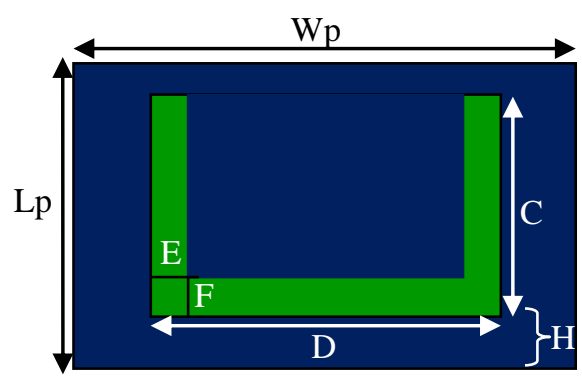

Gambar 2. Antena mikrostrip rectangular slot $U$

Gambar 2 adalah bentuk antena mikrostrip rectangular dengan penambahan slot U. Untuk mencari lebar dan panjang antena mikrostrip digunakan persamaan (2-6) seperti berikut [9]:

- Menentukan Lebar Patch ( Wp ) $W p=1.5(L p+2 \Delta L)$.

Dimana :

$$
L p+2 \Delta L=\frac{c}{2 f_{0} \sqrt{\varepsilon_{r}}}
$$

- Menentukan Panjang Patch (Lp)

$$
L p=\frac{c}{2 f_{0} \sqrt{\varepsilon_{r}}}-2 \Delta L .
$$

$\Delta L$ merupakan pertambahan panjang dari L akibat adanya fringing effect.

$$
\begin{aligned}
& \Delta L=0.412 h \frac{\left(\varepsilon_{\text {reff }}+0.3\right)\left(\frac{W}{h}+0.262\right)}{\left(\varepsilon_{\text {reff }}-0.258\right)\left(\frac{W}{h}+0.813\right)} \ldots \ldots . .(5) \\
& \varepsilon_{\text {reff }}=\frac{\varepsilon_{r}+1}{2}+\frac{\varepsilon_{r}-1}{2}\left(\frac{1}{\sqrt{1+12 \frac{h}{W}}}\right) \ldots(6)
\end{aligned}
$$

Pada Gambar 2 terlihat sebuah antena mikrostrip yang dipotong simetris pada pusat patch berupa bidang berbentuk U. Pemotongan ini mengakibatkan pelebaran bandwidth antena. Bandwidth yang lebar dihasilkan ketika slot dirancang mampu menghasilkan frekuensi resonansi yang berdekatan dengan frekuensi resonansi antena sebelum diberi slot.

Untuk menentukan dimensi slot $U$ digunakan persamaan (7-10) seperti berikut [10] :

- Ketebalan Slot ( E dan F)

$$
E=F=\frac{\lambda_{0}}{60} \text {. }
$$

Dimana $\lambda_{0}$ adalah panjang gelombang pada frekuensi tengah ( $\left.f_{0}\right)$. 
- Lebar Slot ( D )

$$
D=\frac{c}{\sqrt{\varepsilon_{\text {reff }}} f_{\text {low }}}-2(L+2 \Delta L-E)
$$

- Tinggi Slot ( C )

$$
\frac{C}{D} \geq 0.75
$$

- Posisi Slot dari patch ( $\mathrm{H})$

$H \approx L-E+2 \Delta_{L-E-H}-\frac{1}{\sqrt{\varepsilon_{e f f}(p p)}}\left[\frac{c}{f_{u p}}-(2 C+D)\right] \ldots$

Dimana panjang tambahan efektif ( $2 \Delta_{L-E-H}$ ) dihitung dengan persamaan (11) dan konstanta dielektrik efektif pseudopatch $\left(\varepsilon_{\text {eff }(p p)}\right)$ dihitung dengan menggunakan persamaan (12).

$$
\begin{aligned}
& 2 \Delta_{L-E-H}=0.824 h \frac{\left(\varepsilon_{e f f(p p)}+0.3\right)\left(\frac{D-2 F}{h}+0.262\right)}{\left(\varepsilon_{e f f(p p)}-0.258\right)\left(\frac{D-2 F}{h}+0.813\right)} \ldots( \\
& \varepsilon_{e f f(p p)}=\frac{\varepsilon_{r}+1}{2}+\frac{\varepsilon_{r}-1}{2}\left(\frac{1}{\sqrt{1+\frac{12 h}{D-2 F}}}\right) \ldots(
\end{aligned}
$$

\subsection{Microstrip transmission line feed}

Teknik pencatuan ini mudah untuk di pabrikasi dan di-matchingkan dengan cara mengatur posisi insertnya. Pencatuan dilakukan dengan cara menghubungkan line pencatuan dengan patch, dimana patch dan line pencatuan menggunakan bahan yang sama. Untuk mendapatkan impedansi input antena yang sebanding dengan impedansi karakteristik dari saluran pencatu, dapat dilakukan dengan mengubah-ubah dimensi dari elemen pencatu. Untuk menentukan dimensi dari saluran pencatu ( $\mathrm{Lm}$ ) dapat menggunakan persamaan berikut [11]:

$$
L_{m}=\frac{c}{4 f_{0} \sqrt{\varepsilon_{r}}}
$$

Keterangan :
$\mathrm{L}_{\mathrm{m}}$ : panjang saluran pencatu
$\varepsilon_{\mathrm{r}}:$ konstanta dielektrik
c : kecepatan cahaya
$\mathrm{f}_{0}:$ frekuensi tengah antena

Persamaan (13) digunakan untuk menentukan panjang dari saluran pencatu $\mathrm{L}_{\mathrm{m}}$. Lebar pencatu sangat dipengaruhi oleh tinggi/ketebalan bahan substrate (h) dan jenis bahan substrate yang digunakan [11]. Untuk lebar pencatu $(\mathrm{Wm})$ kita gunakan persamaan (14) dan (15).:

$$
W_{m}=\frac{8 \cdot h \cdot \exp (A)}{\exp (2 A)-2}
$$

Dimana :

$$
A=\frac{z_{0}}{60}\left\{\frac{\varepsilon_{r}+1}{2}\right\}^{1 / 2}+\frac{\varepsilon_{r}-1}{\varepsilon_{r}+1}\left\{0.23+\frac{0.11}{\varepsilon_{r}}\right\} \text {. }
$$

Sedangkan posisi terbaik saluran pencatu terhadap lebar patch adalah diposisi tengah jika lebar patch besar sama dengan panjang patch [12].

\subsection{Impedansi Matching}

Perancangan suatu antena tidak akan terlepas dari penyesuaian impedansi [3]. Suatu jalur transmisi dikatakan matched apabila karakteristik impedansi $\mathrm{Z}_{0}=\mathrm{Z}_{\mathrm{L}}$ atau bisa dikatakan tidak ada refleksi yang terjadi pada ujung saluran beban. $Z_{0}$ adalah karakteristik impedansi suatu saluran transmisi yang biasanya bernilai $50 \mathrm{ohm}$, dan $\mathrm{Z}_{\mathrm{L}}$ adalah impedansi beban. Beban dapat berupa antena atau rangkaian lain yang mempunyai impedansi ekivalen $Z_{L}$. Pada prinsipnya, untuk menyesuaikan impedansi saluran dengan impedansi beban, maka disisipkan suatu "transformator impedansi" yang berfungsi mengubah impedansi beban agar sama dengan impedansi karakteristik saluran. Pada penelitian ini digunakan teknik transformator $\lambda / 4$ untuk memperoleh keadaan impedance matching. Transformator $\lambda / 4$ merupakan teknik impedance matching dengan menambahkan saluran transmisi dengan impedansi $\mathrm{Z}_{\mathrm{T}}$ diantara dua saluran yang tidak match. Nilai impedansi $Z_{T}$ dapat dihitung dengan persamaan (16) berikut :

$$
Z_{T}=\sqrt{Z_{o} \times Z_{L}}
$$

\subsection{T-Junction Power Divider}

Power divider (combiner) merupakan salah satu teknik yang dapat mendukung impedance matching pada saluran transmisi khususnya untuk antena mikrostrip array. T-junction memiliki struktur yang sederhana yang membutuhkan ruang minimum yang memungkinkan penggunaan substrat dengan permitifitas yang rendah dan memungkinkan energi yang tidak seimbang yang menghasilkan pelonjongan amplitude dan peningkatan level side lobe. Kelemahan yang ditemukan dari t-junction sendiri adalah memiliki 
tingkat isolasi yang buruk diantara output (sekitar $6 \mathrm{~dB})$ [13].

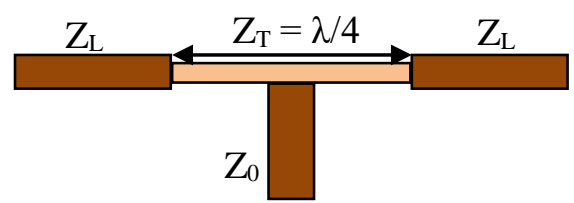

Gambar 3. Rangkaian T-junction saluran mikrostrip

Gambar 3 merupakan rangkaian T-junction saluran mikrostrip. Ada ketentuan dasar yang dibutuhkan untuk membentuk power divider jenis ini, yaitu feedline harus matching, dan daya input $\left(\mathrm{P}_{\text {in }}\right)$ harus terbagi ke port 1 dan port 2 dengan perbandingan yang diinginkan [8]. Misalkan perbandingan daya yang diinginkan sebesar 1:1 maka setiap port akan menerima daya sebesar $50 \%$ dari daya input. Untuk mendapatkan ketentuan dasar agar feedline harus matching, maka berdasarkan pembagian daya pada masingmasing port, maka didapatkan persamaan untuk mencari impedansi masing-masing port seperti persamaan (17).

$$
Y_{\text {in }}=\frac{1}{Z_{1}}+\frac{1}{Z_{2}}=\frac{1}{Z_{0}}
$$

Lebar saluran pencatu $\mathrm{T}$ junction sangat dipengaruhi oleh tinggi atau ketebalan bahan substrat (h) dan jenis bahan substrat yang digunakan [14]. Lebar saluran pencatu T-junction terlihat pada persamaan (18).

$$
W_{m}=\frac{k}{z_{0}} x \frac{\mathrm{h}}{\sqrt{\varepsilon_{r}}}(\mathrm{~mm})
$$

Keterangan :

$\mathrm{Wm}$ : lebar saluran pencatu $\mathrm{T}$ junction $(\mathrm{mm})$

$\mathrm{k}$ : impedansi karakteristik ruang bebas

$(120 \pi \Omega)$

$\mathrm{h} \quad$ : tebal substrat ( $\mathrm{mm})$

$\varepsilon_{\mathrm{r}} \quad:$ konstanta dielektrik $(\mathrm{F} / \mathrm{m})$

$\mathrm{Z}_{0} \quad$ : impedansi input ( $50 \Omega$ )

\section{Diagram Alir Penelitian}

Secara garis besar, tahapan pada perancangan antena ini terbagi menjadi dua tahap, yaitu tahap perancangan antena elemen tunggal dan perancangan antena elemen array. Bentuk diagram alir dari penelitian ini dapat dilihat pada Gambar 4.

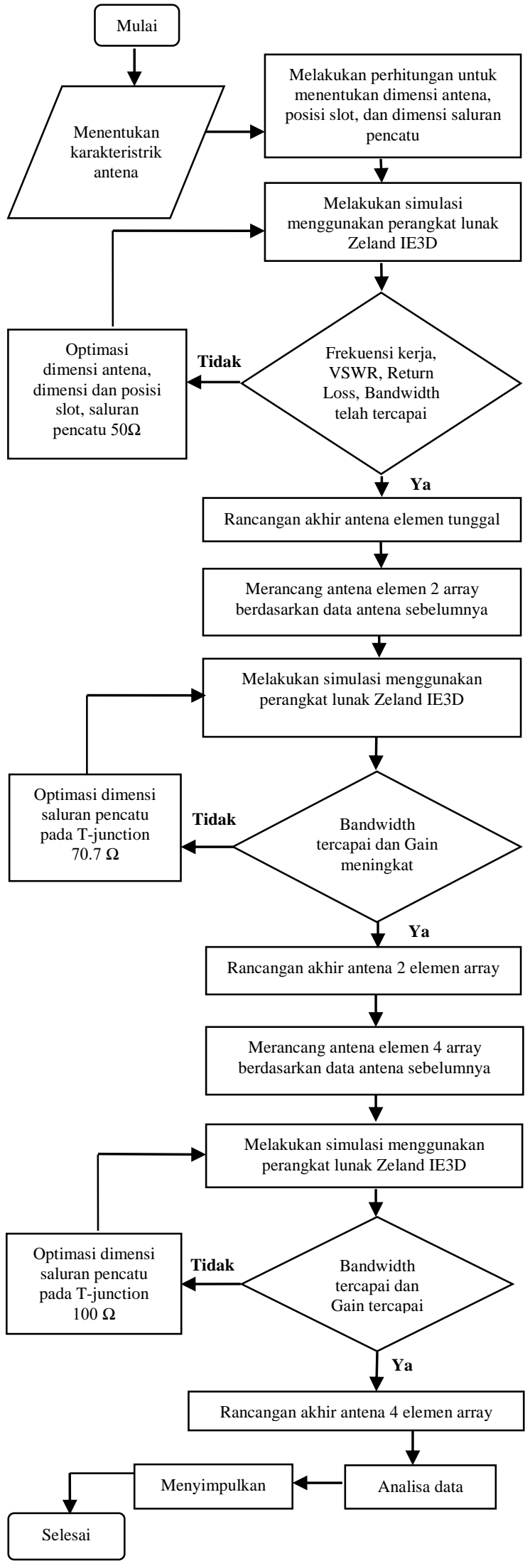

Gambar 4. Diagram alir penelitian 
Pada penelitian ini dirancang sebuah antena mikrostrip rectangular dengan penambahan slot berbentuk huruf $U$ dan disusur secara linear.

Ada beberapa tahapan dalam perancangan antena ini, diantaranya adalah penentuan spesifikasi substrat yang akan digunakan, penentuan dimensi antena dan dimensi slot serta penentuan dimensi saluran pencatu. Hasil rancangan tersebut kemudian disimulasikan dengan menggunakan perangkat lunak Zeland IE3D.

Hasil akhir dari perancangan antena mikrostrip ini adalah berupa antena mikrostrip rectangular slot U yang disusun empat linear array dan sesuai dengan parameter yang diharapkan, seperti terlihat pada Gambar 5.

Antena yang dirancang dapat bekerja pada rentang frekuensi $486 \mathrm{Mhz}$ sampai $734 \mathrm{Mhz}$ dengan frekuensi tengah 610 Mhz. Pemilihan rentang frekuensi kerja tersebut dimaksudkan agar antena dapat menerima semua siaran televisi terrestrial di kota padang dengan baik. Antena yang dirancang memiliki VSWR $\leq 2$ sehingga menghasilkan return loss $\leq-9,5 \mathrm{~dB}$. Antena mikrostrip yang dirancang pada penelitian ini menggunakan substrat dengan spesifikasi, jenis FR4 Epoxy, konstanta dielektrik 4.7, dielektrik loss tangen 0.02 dan tebal $1.6 \mathrm{~mm}$

\subsection{Return Loss}

Nilai return loss yang didapatkan pada perancangan telah memenuhi karakterstik yang diinginkan. Dimana pada Gambar 6 terlihat semua frekuensi yang masuk kedalam frekuensi kerja antena memiliki return loss berada dibawah -9.5 $\mathrm{dB}$.

\section{Hasil dan Pembahasan}

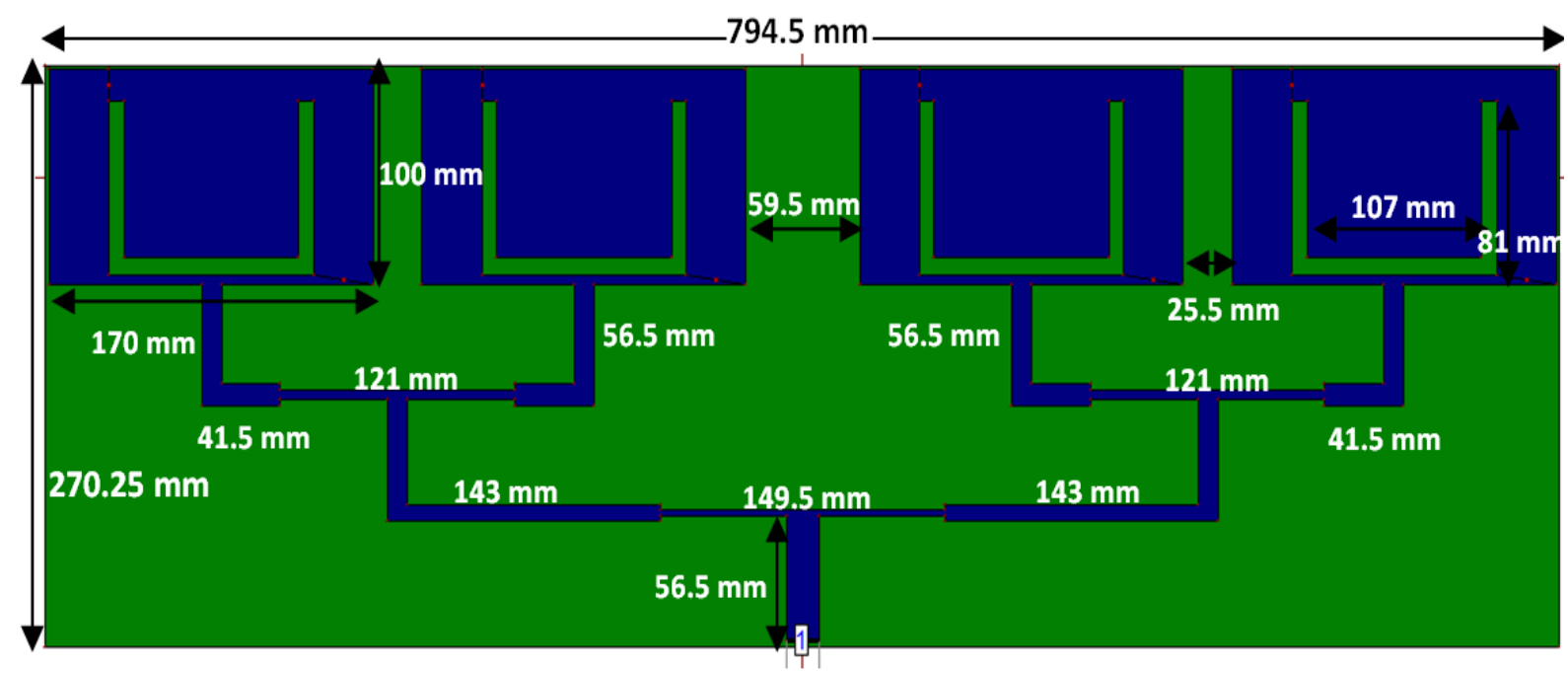

Gambar 5. Hasil akhir perancangan antena 4 elemen array

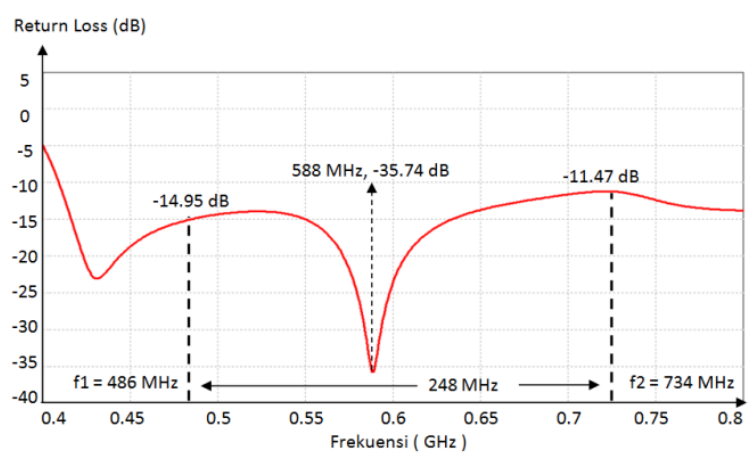

Gambar 6. Return Loss antena 4 elemen array
Return loss pada frekuensi $486 \mathrm{MHz}$ adalah 14,95 dB, pada frekuensi $610 \mathrm{MHz}$ adalah $-19,18$ $\mathrm{dB}$, dan pada frekuensi $734 \mathrm{MHz}$ adalah 11,47 $\mathrm{MHz}$. Return loss terbaik berada pada frekuensi $588 \mathrm{MHz}$ yaitu $-35,74 \mathrm{~dB}$.

\subsection{VSWR}

Dari Gambar 7 terlihat bahwa bandwidth yang didapatkan melebihi bandwidth yang diharapkan. Hal ini tidaklah jadi masalah karena bisa digunakan filter untuk menyaring frekuensi yang 
tidak diinginkan dan memproses frekuensi yang diinginkan.

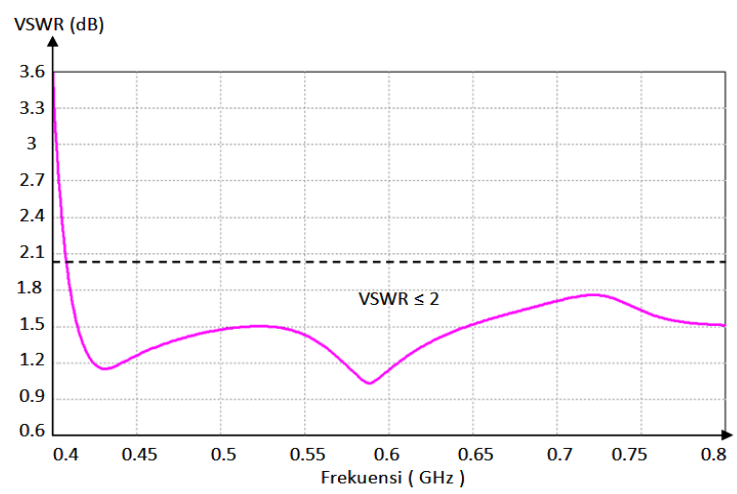

Gambar 7. VSWR antena 4 elemen array

\subsection{Pola Radiasi}

Jenis pola radiasi yang terbentuk memiliki jenis pola radiasi bidirectional, yang meradiasikan gelombangnya pada dua arah yang berlawanan. Pola radiasi arah horizontal dapat dilihat pada Gambar 8 berikut.



Gambar 8. Pola radiasi antena arah horizontal

Pada Gambar 8 terlihat bahwa pola radiasi horizontal maksimum dicapai pada sudut 40 derajat dan 140 derajat.

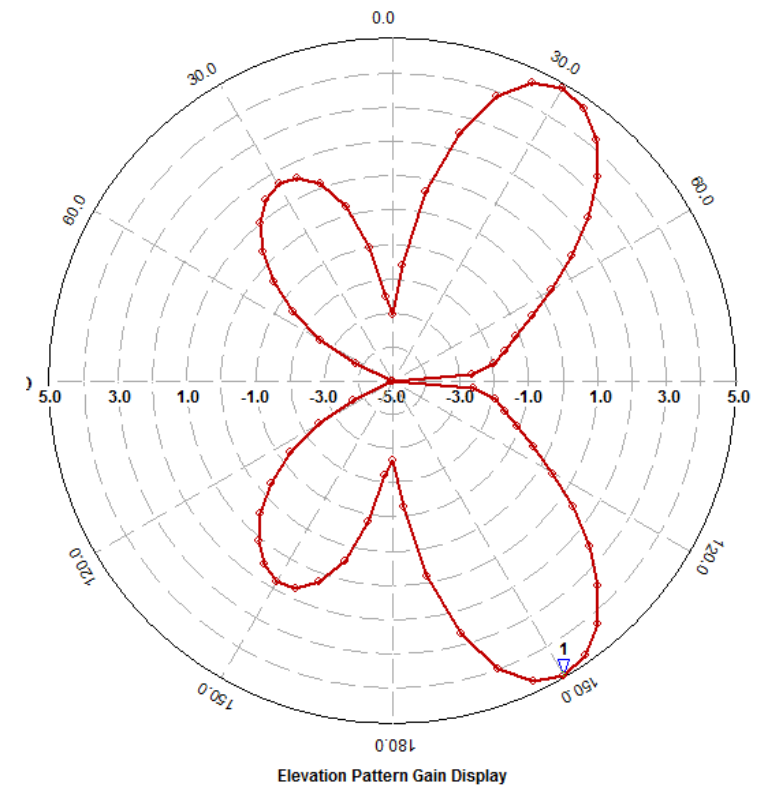

Gambar 9. Pola radiasi antena arah vertikal

Pola radiasi arah vertikal dapat dilihat pada Gambar 9 diatas. Pola radiasi maksimum dicapai pada sudut 30 dan 150 derajat.

\subsection{Gain}

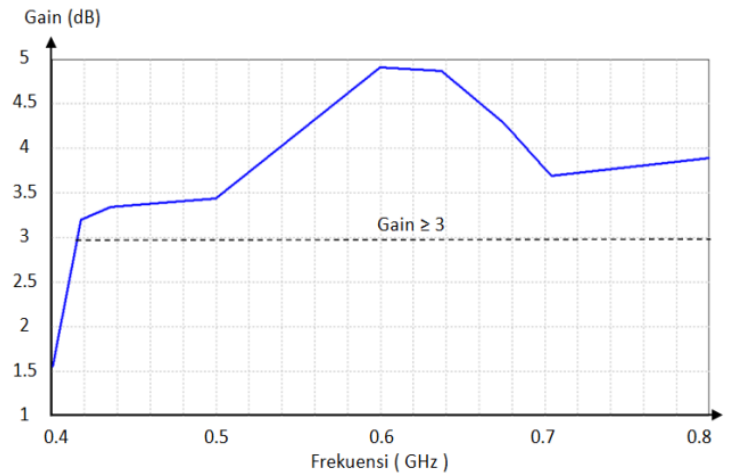

Gambar 10. Gain antena 4 elemen array

Gain yang didapatkan untuk seluruh frekuensi yang berada pada rentang $486 \mathrm{MHz}$ sampai 734 $\mathrm{MHz}$ seperti yang terlihat pada gambar 10 berada di atas $3 \mathrm{~dB}$. Sehingga dapat dikatakan bahwa rancangan telah memenuhi target yang diinginkan.

\section{Kesimpulan}

Pada penelitian ini telah dirancang sebuah antena mikrostrip linear array dengan slot $\mathrm{U}$ untuk aplikasi sebagai antena internal pada pesawat Televisi (TV). Antena yang dirancang sesuai untuk TV dengan ukuran minimal 32 inch. Hasil 
simulasi dengan Zeland IE3D memperlihatkan bahwa antena dapat bekerja dengan baik pada keseluruahan rentang frekuensi UHF yaitu pada frekuensi 486 - $734 \mathrm{MHz}$ dengan Gain diatas 3.5 dB.

\section{Daftar Pustaka}

[1] Lifwarda.. Pembuatan Antena Mikrostrip Model Angka 4 Untuk Penerima Sinyal Televisi Pada Jalur UHF. Jurnal Elektron Vol 5 No.2. 2013

[2] Al Rizqy, M. Hidayat.. Simulasi dan Implementasi Antena Mikrostrip Bentuk Trisula Sebagai Aplikasi Penerima TV Digital. Jurnal Transmisi Vol 15 No.3. 2013

[3] Ainur Ridho, vicky.. Perancangan dan Realisasi Antena Mikrostrip $700 \mathrm{MHz}$ Model Patch Circular Dengan Metode Linear Array Sebagai Penerima TV Digital. Jurnal Arus Elektro Indonesia vol 1 No.3. 2015

[4] Dawre, R.K, dan Rani, Aruna.. Design and Analysis of Rectangular and U Slotted Microstrip Patch using Optimization Program in Java for UHF Applications. International Journal of Computer Applications Vol 3, No.5. 2010

[5] Ansari, J. A. dan R. B. Ram. Broadband Stacked U-Slot Microstrip Patch Antenna. Progress in Electromagnetics Research Letters Vol. 4: 12-24. 2008

[6] Balanis, Constantine A, , Antena Theory Analysis and Design, third edition, Willey inc. 2005

[7] Garg Ramesh, , Microstrip Antenna Design Handbook, Artech House, hal.1 30 dan 425 - 436. 2001

[8] Fahrazal, Muhammad. Rancang Bangun Antena Mikrostrip Triple Band Linear Array 4 Elemen Untuk Aplikasi Wimax. Penelitian. Universitas Indonesia. 2008.

[9] Ishfaq Muhammad and Khan, Sheharyar Raja. A Compact Microstrip Patch Antenna for LTE Applications. Master Tesis. School of Computer Science, Physics and Mathematics. Linnaeus University. Swedia. 2013.

[10] Tong, Chin Hong Matthew. System Study and Design of Broadband U-Slot
Microstrip Patch Antennas for Aperstructures and Opportunistic Arrays. Thesis. California: Naval Postgraduate School. 2005.

[11] Md. Tanvir Ishtaique-ul Huque, Md. Kamal Hosain, Md. Shihabul Islam, and Md. Al-Amin Chowdhury, Design and Performance Analysis of Microstrip Array Antennas with Optimum Parameters for $X$-band Applications. International Journal of Advanced Computer Science and Applications Vol 2 No.4. 2011

[12] Erfan Achmad Dahlan. Perencanaan Dan Pembuatan Antena Mikrostrip Array 2x2 Pada Frekuensi 1575 Mhz. Jurnal EECCIS Vol. III No. 1. 2009.

[13] Barbetty, Mauricio Sánchez. Design And Implementation of A Transceiver And A Microstrip Corporate Feed For Solid State $X$ Band Radar. Penelitian. University Of Puerto Rico Mayagüez Campus. 2005.

[14] Whites, Keith W. Lecture 24 :T-junction and Resistive Power dividers. EE 481. 2013.

\section{Biodata Penulis}

Aditya Wardhani, lahir pada tanggal 20 Juli 1986 di Padang. Penulis merupakan alumni Jurusan Teknik Elektro, Fakultas Teknik, Universitas Andalas dan sekarang sedang melanjutkan studi pada Program Studi S2 Teknik Elektro Universitas Andalas.

Ikhwana Elfitri, menyelesaikan pendidikan Sarjana dan Magister pada bidang Teknik Telekomunikasi di Institut Teknologi Bandung (ITB) dan Doktoral pada Department of Electronics, University of Surrey, Inggris. Saat ini Dr. Elfitri bekerja sebagai dosen dengan jabatan akademik Lektor Kepala pada Jurusan Teknik Elektro, Universitas Andalas. Sejak tahun 2011, ia telah secara aktif menjadi reviewer pada beberapa jurnal ilmiah termasuk IEEE Transaction on Multimedia dan IET Signal Processing. Dr. Elfitri adalah member the Institute of Electrical and Electronics Engineer (IEEE) sejak tahun 2012 dan Audio Engineering Society (AES) mulai tahun 2015. 